\section{Re: Nonmelanomatous Skin Cancer Following Cervical, Vaginal, and Vulvar Neoplasms: Etiologic Association}

Levi et al. (1) report elevated standardized incidence ratios (SIRs) for nonmelanomatous skin cancer (NMSC) in women listed with cervical and vulvar/vaginal cancers in the Vaud cancer registry, Vaud, Switzerland. This finding is interpreted as support for a role of human papillomaviruses (HPVs) in the etiology of NMSC. We feel prompted to comment on this interpretation and to present additional observations that may help clarify the topic.

We identified all women reported to the national cancer registry in Denmark with invasive cervical, vulvar/vaginal, and anal cancers during the period from 1943 through 1990 and all women with cervical intraepithelial neoplasia (grade III) or carcinoma in situ during the period from 1958 through 1990. Women with colorectal, breast, and uterine corpus cancers (all HPV unassociated) during the period from 1943 through 1990 were also identified. We followed all women for new cancers and calculated SIRs and $95 \%$ confidence intervals based on the Poisson distribution as described previously (2).

SIRs for cancer overall were significantly elevated in all anogenital cancer cohorts (SIR = 1.13-1.49), and SIRs for NMSC were also consistently elevated $(\mathrm{SIR}=1.20-1.81)$. Women with HPV-unassociated cancers also had elevated SIRs for NMSC (SIR = 1.141.35) (Table 1).

The number of expected cancers, and thus the size of the SIR, depend on the completeness of cancer registration in the population at large. Levi et al. (3) previously considered underregistration of NMSCs to be substantial, but they did not discuss this important point in their recent letter (1). What their SIR estimates tell is that women registered with cervical and vulvar/vaginal malignancies in Vaud, Switzerland, are statisti- cally more likely also to have a subsequent registered NMSC than other women in that population. We found similar statistical associations for women with anogenital cancers in Denmark but elevated SIRs for NMSC were not a specific finding. Patients with anogenital cancer had significantly increased SIRs for cancer in general, a context hardly justifying speculations about the possible etiologic involvement of (anogenital types of) HPV in NMSCs. Moreover, patients with HPV-unassociated cancers also had elevated SIRs for NMSC, which renders the proposed role of HPV in NMSC even less appealing.

Important common characteristics for all the women studied may be the close clinical follow-up and an increased individual alertness toward new symptoms. Recalling the problem of underregistration, patients whose NMSCs actually end up in cancer registries may well be those who, for a variety of reasons, have close contact to the health care system.

The finding that patients with NMSC are not at any increased subsequent cervical cancer risk $(4,5)$ was recently confirmed by Levi et al. (6). This lack of an association further detracts from the idea that anogenital HPV types are involved in NMSCs. Inference of biologic significance from epidemiologic associations should not rest on statistical significance alone. Repeated, unsuccessful attempts to explain a new association by potential limitations in the data should precede etiologic speculations. Such considerations often favor alternative,

Table 1. Observed and expected cases and standardized incidence ratios (SIRs) of subsequent cancers (overall) and nonmelanomatous skin cancers among women with anogenital cancers, colorectal cancer, breast cancer, and cancer of the uterine corpus in Denmark during the period from 1943 through 1990*

\begin{tabular}{|c|c|c|c|c|c|c|c|c|}
\hline \multirow[b]{2}{*}{ Site of primary tumor } & \multirow[b]{2}{*}{$\begin{array}{l}\text { No. of } \\
\text { patients }\end{array}$} & \multirow[b]{2}{*}{$\begin{array}{c}\text { No. of } \\
\text { person-years }\end{array}$} & \multicolumn{3}{|c|}{ All cancers } & \multicolumn{3}{|c|}{ Nonmelanomatous skin cancers } \\
\hline & & & $\begin{array}{c}\text { No. } \\
\text { observed }\end{array}$ & $\begin{array}{c}\text { No. } \\
\text { expected }\end{array}$ & $\begin{array}{c}\text { SIR } \\
(95 \% \mathrm{CI} \dagger)\end{array}$ & $\begin{array}{c}\text { No. } \\
\text { observed }\end{array}$ & $\begin{array}{c}\text { No. } \\
\text { expected }\end{array}$ & $\begin{array}{c}\text { SIR } \\
(95 \% \mathrm{CI} \dagger)\end{array}$ \\
\hline \multicolumn{9}{|c|}{$H P V+$-associated anogenital cancers } \\
\hline Cervix, preinvasive $\S$ & 30294 & 374640 & 2212 & 1801.9 & $1.23(1.18-1.28)$ & 263 & 190.0 & $1.38(1.22-1.56)$ \\
\hline Cervix, invasive & 32307 & 360290 & 3399 & 3020.0 & $1.13(1.09-1.16)$ & 362 & 295.8 & $1.22(1.10-1.36)$ \\
\hline Vulva/vagina & 3840 & 23956 & 360 & 297.0 & $1.21(1.09-1.34)$ & 60 & 33.2 & $1.81(1.38-2.33)$ \\
\hline Anus & 684 & 3724 & 65 & 43.6 & $1.49(1.15-1.90)$ & 6 & 5.0 & $1.20(0.44-2.61)$ \\
\hline \multicolumn{9}{|c|}{$H P V \ddagger-u n a s s o c i a t e d$ cancers } \\
\hline Colon/rectum & 54635 & 197300 & 2800 & 2665.5 & $1.05(1.01-1.09)$ & 371 & 308.0 & $1.20(1.08-1.33)$ \\
\hline Breast & 85243 & 589484 & 6122 & 6384.2 & $0.96(0.94-0.98)$ & 929 & 688.8 & $1.35(1.26-1.44)$ \\
\hline Uterine corpus & 19254 & 178442 & 2172 & 2147.9 & $1.01(0.97-1.05)$ & 267 & 234.4 & $1.14(1.01-1.28)$ \\
\hline
\end{tabular}

*Inclusion period restricted to the period from 1958 through 1990 for women with preinvasive cervical cancer.

$\dagger \mathrm{CI}=$ confidence interval.

$\ddagger \mathrm{HPV}=$ human papillomavirus.

§omen diagnosed with cervical carcinoma in situ or cervical intraepithelial neoplasia (grade III) are included. 
usually less spectacular, explanations of new findings. Other HPV types may be involved, but current epidemiologic and molecular biologic evidence still does not suggest the involvement of anogenital HPV types in most NMSCs (7).

\section{MORTEN FRISCH HENRIK HJALGRIM}

\section{REFERENCES}

(1) Levi F, Randimbison L, La Vecchia C. Nonmelanomatous skin cancer following cervical, vaginal, and vulvar neoplasms: etiologic association [letter]. J Natl Cancer Inst 1998;90: $1570-1$.

(2) Frisch M, Melbye M. Risk of lung cancer in pre- and post-menopausal women with anogenital malignancies. Int J Cancer 1995;62: 508-11.

(3) Levi F, La Vecchia C, Te VC, Mezzanotte G. Descriptive epidemiology of skin cancer in the Swiss Canton of Vaud. Int J Cancer 1988;42: 811-6.

(4) Frisch M, Melbye M. New primary cancers after squamous cell skin cancer. Am J Epidemiol 1995;141:916-22.

(5) Frisch M, Hjalgrim H, Olsen JH, Melbye M. Risk for subsequent cancer after diagnosis of basal-cell carcinoma. A population-based, epidemiologic study. Ann Intern Med 1996;125: 815-21.

(6) Levi F, La Vecchia C, Te VC, Randimbison L, Erler G. Incidence of invasive cancers following basal cell skin cancer. Am J Epidemiol 1998;147:722-6.

(7) de Villiers EM. Human papillomavirus infections in skin cancers. Biomed Pharmacother 1998;52:26-33.

\section{Notes}

Affiliation of authors: Department of Epidemiology Research, Danish Epidemiology Science Center, Statens Serum Institut, Copenhagen, Denmark.

Correspondence to present address: Morten Frisch, M.D., Ph.D., Viral Epidemiology Branch, Division of Cancer Epidemiology and Genetics, National Cancer Institute, National Institutes of Health, Executive Plaza South, Rm. 8015, Rockville, MD 20852 (e-mail: Frischm@mail.nih.gov).

Supported by The Direktor E. Danielsen og Hustrus Foundation, The Foundation for the Advancement of Medical Science, and The Danish Cancer Society (grant 96-100-17).

\section{RESPONSE}

Frisch and Hjalgrim suggest that increased diagnosis of nonmelanomatous skin cancer may, partly or totally, explain the excess incidence observed after diagnosis of cervical, vaginal, or vulvar neoplasms in the Vaud cancer registry dataset (1).

Such a differential diagnostic attention is a function of the completeness of registration of nonmelanomatous skin

Table 1. Observed and expected cases of cancer and standardized incidence ratios (SIRs), with corresponding 95\% confidence intervals (CIs), of subsequent cancers (overall) and nonmelanomatous skin cancers among women with colorectal cancer, breast cancer, and cancer of the uterine corpus in Vaud, Switzerland, during the period from 1974 through 1994

\begin{tabular}{|c|c|c|c|c|c|c|}
\hline \multirow[b]{2}{*}{$\begin{array}{l}\text { Site of } \\
\text { primary tumor }\end{array}$} & \multicolumn{3}{|c|}{ All cancers } & \multicolumn{3}{|c|}{ Nonmelanomatous skin cancers } \\
\hline & $\begin{array}{c}\text { No. } \\
\text { observed }\end{array}$ & $\begin{array}{c}\text { No. } \\
\text { expected }\end{array}$ & $\begin{array}{c}\text { SIR } \\
(95 \% \mathrm{CI})\end{array}$ & $\begin{array}{c}\text { No. } \\
\text { observed }\end{array}$ & $\begin{array}{c}\text { No. } \\
\text { expected }\end{array}$ & $\begin{array}{c}\text { SIR } \\
(95 \% \mathrm{CI})\end{array}$ \\
\hline Colorectum & 142 & 155.5 & $0.9(0.8-1.1)$ & 32 & 41.4 & $0.8(0.5-1.1)$ \\
\hline Breast & 479 & 405.7 & $1.2(1.1-1.3)$ & 122 & 104.7 & $1.2(1.0-1.4)$ \\
\hline Uterine corpus & 94 & 110.6 & $0.9(0.7-1.0)$ & 26 & 28.5 & $0.9(0.6-1.3)$ \\
\hline
\end{tabular}

cancer. This completeness is uniquely high in the Vaud population, which has long been particularly well surveyed with reference to skin neoplasms. In this area, in fact, surgically resected cutaneous lesions have traditionally been examined pathologically, and incidence data of nonmelanomatous skin cancers from this registry have been used as reference estimates over the last two decades (2-4). Thus, registered incidence of nonmelanomatous skin cancers during the period from 1988 through 1992 was appreciably higher in Vaud (100 cancers per 100000 males and 76 cancers per 100000 females; world standard) than in Denmark (53 cancers per 100000 males and 43 cancers per 100000 females) (5). This should have substantially reduced any potential ascertainment bias in our Swiss population.

This line of reasoning is supported also by the appreciably stronger excess risk in our dataset (overall standardized incidence ratio [SIR] after cervical, vaginal, and vulvar cancers $=2.1 ; 95 \%$ confidence interval $=1.6-2.7)$ compared with an SIR of 1.3 (685 observed versus 519 expected cases) in the Danish dataset. This excess risk of more than twofold can hardly be explained only by surveillance or ascertainment bias. Further support for this view comes from Table 1, which gives expected and observed numbers of all neoplasms and of nonmelanomatous skin neoplasms during the period from 1974 through 1994 [thus updating a previous report (6)] after colorectal, breast, and endometrial cancers, i.e., the three neoplasms unlikely to be related to human papillomavirus infection selected by Frisch and Hjalgrim. The SIRs for none of these neoplasms were above unity or materially different between nonmelanomatous skin neoplasms and other cancers. Thus, in the Vaud population, incidence of nonmelanomatous skin cancer is elevated after human papillo- mavirus-related neoplasms but not after other selected cancers. Likewise, in the Swedish record-linkage cohort study (7), the incidence of cervical, vulvar, and vaginal cancers was significantly elevated in patients with squamous cell carcinoma of the skin.

\section{FABIo LeVI LALAO RANDIMBISON CARLo La Vecchia}

\section{REFERENCES}

(1) Levi F, Randimbison L, La Vecchia C. Nonmelanomatous skin cancer following cervical, vaginal, and vulvar neoplasms: etiologic association [letter]. J Natl Cancer Inst 1998;90: 1570-1.

(2) Lee JA. Melanoma and exposure to sunlight. Epidemiol Rev 1982;4:110-36.

(3) Levi F, La Vecchia C, Te VC, Mezzanotte G. Descriptive epidemiology of skin cancer in the Swiss Canton of Vaud. Int J Cancer 1988:42: 811-6.

(4) Levi F, Franceschi S, Te VC, Randimbison L, La Vecchia C. Trends of skin cancer in the Canton of Vaud, 1976-92. Br J Cancer 1995; 72:1047-53.

(5) Levi F, Lucchini F, Boyle P, Negri E, La Vecchia C. Cancer incidence and mortality in Europe. J Epidemiol Biostat 1998;3:295-373.

(6) Levi F, Randimbison L, Te VC, RollandPortal I, Franceschi S, La Vecchia C. Multiple primary cancers in the Vaud Cancer Registry, Switzerland, 1974-89. Br J Cancer 1993;67: 391-5.

(7) Wassberg C, Thorn M, Yuen J, Ringborg U, Hakulinen T. Second primary cancers in patients with squamous cell carcinoma of the skin: a population-based study in Sweden. Int J Cancer 1999;80:511-5.

\section{Notes}

Affiliations of authors: F. Levi, L. Randimbison, Registre Vaudois des Tumeurs, Institut Universitaire de Médecine Sociale et Préventive, Lausanne, Switzerland; C. La Vecchia, Istituto di Ricerche Farmacologiche "Mario Negri," and Istituto di Statistica Medica e Biometria, Università degli Studi di Milano, Milan, Italy.

Correspondence to: Fabio Levi, M.D., Registre Vaudois des Tumeurs, CHUV-Falaises 1, CH1011 Lausanne, Switzerland (e-mail: fabio.levi@ inst.hospvd.ch). 